\title{
CONSIDERAÇÕES SOBRE A CRIAÇÃO DE PEIXES ESTUARINOS EM VIVEIROS
}

\author{
HITOSHI NOMURA
}

Faculdade de Filosofia, Ciências e Letras de Rlbeirăo Preto, Ribeirăo Preto, SP, Brasli

\section{SYNOPSIS}

During the spawning period, fishes of the familes Mugilidae and Centropomidae concentrate on the river mouths or brackishwater lagoons. Those species are reared in fish-ponds ("viveinos") in northeastern Brazil, mainly at Pernambuco State. Presently, polyculture trials are made with those species, together with three others of the family Gerridae, with or without artificial feeding or fertilization. The yields are very high per ha/year. A review of the biology of those species, together with the hydrological conditions of the fish-ponds, are presented. The author recommends that similar fish-ponds should be built in other northeastern regions as well as in the south, and the obtention of fry through hypophysation method (now used in Israel and Taiwan for Mugilidae), replacing the present method of simply catching younga measuring 10 to $15 \mathrm{~cm}$ total length and putting them in those fish-ponds. In this way we would contribute to a high and quick production of animal protein, necessery to a great part of Brazilian population.

\section{Introduçẫo}

Uma das maneiras de aumentar a produção anual de carne é criar animais aquáticos (peixes, crustáceos, moluscos), mas o sucesso da aqüicultura depende do conhecimento da biologia desses animais.

Duas familias de peixes possuem representantes que são importantes comercialmente: Mugilidae e Centropomidae. Das várias espécies da primeira família são importantes a Curimã, Mugil lisa (antigamente Mugil brosiliensis) e a tainha. Mugil curema; da segun$\mathrm{da}$, o robalo ou camorim, centropomus undecimalis e camurupeba, centropomus parallelus. Essas espécies são criadas nos viveiros pernambucanos, juntamente com três espécies da familia Gerridae: carapeba-branca, Eugerres olisthostoma, carapeva, Eugerres rhombeus e caratinga, Eugerres brasilianus.

$\mathrm{O}$ autor apresenta uma revisão da biologia dos Mugilidae e dos Centropomidae, assim como as condiçoes hidrológicas dos viveiros pernambucanos e faz algumas recomendaç̋̋es para melhorar a produção de peixes nesses ambientes.

Hidrologia dos viveiros pernambucanos

Os viveiros (Fig. 1) localizados no Canal de Santa Cruz e no Rio Igaraçu, em Itamaracá, Pemambuco, foram estudados quanto à

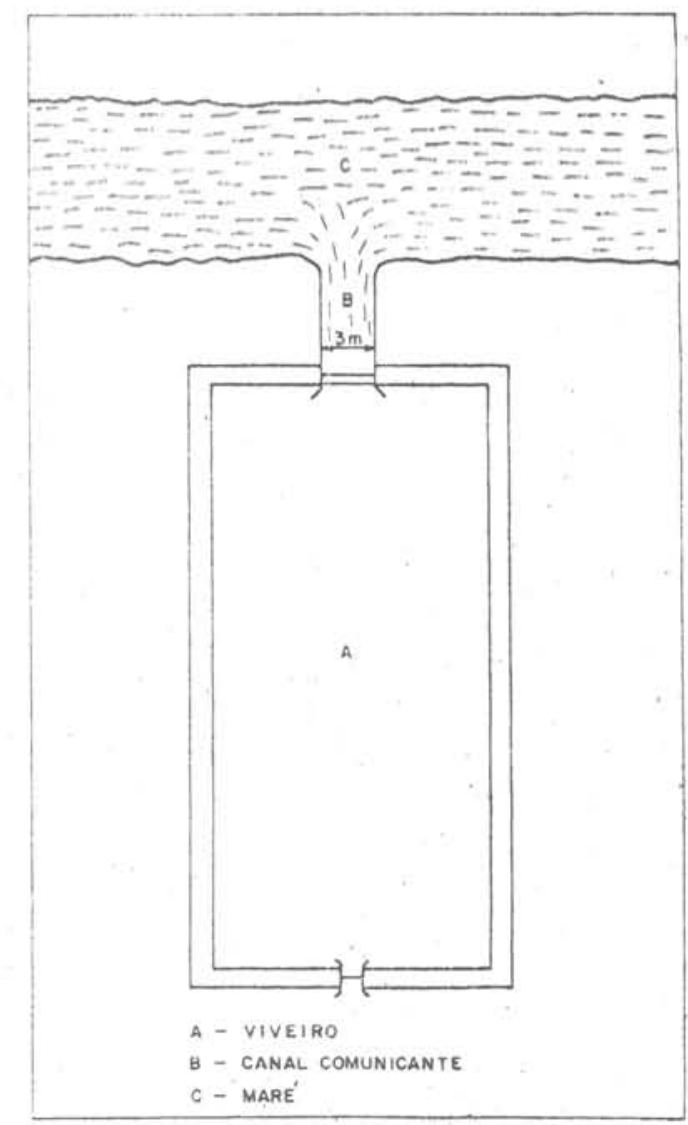

Fig. 1. Esquema de um viveiro (segundo Silva).

salinidade, oxigênio, temperatura e pH durante o verão e o inverno por Silva, Lira \& Macedo (1969). A salinidade tende a aumentar durante o verão, constituindo um obstáculo ao desenvolvimento dos peixes. Os meses críticos se estendem de dezembro a fevereiro, devido à rápida evaporação da água dos viveiros. As espécies criadas são eurihalinasi, mas se a ambiente se torna hiperhalino (salinidade. variando de 43,82 até 47,41 por mil), a quantidade de sais dissolvi- dos torna-se letal para elas. Durante o periodo estudado a temperatura variou de 26,1 a $36,0^{\circ} \mathrm{C}$; o oxigênio dissolvido, de $2,81 \mathrm{ml} / \mathrm{l}$ até $8,00 \mathrm{ml} / \mathrm{l}$, e o pH não foi inferior a 7,7.

As condiçōes físicas e químicas dessas águas e sua variação durante o ano foram estudadas por Macedo, Lira \&Silva (1973). De acordo com eles, uma grande quantidade de água doce flui para o canal durante $\circ$ inverno, vindo dos rios adjacentes, causando uma 
đımınuiçåo da salinídade, temperatura, transparēncia e oxigênio dissolvido, com um conseqüente aumento nos valores nutritivos.

\section{Biologia dos Mugilidae}

Schubart (1936) foi o primeiro pesquisador a estudar a idade, maturidade e parasitos da curimã, Mugil lisa (Fig. 2) e da tainha Mugil curema (Fig. 3). A primeira atinge 39 a $49 \mathrm{~cm}$ no terceiro ano de vida, enquanto que a segunda, $37 \mathrm{a} 41 \mathrm{~cm}$ no mesmo período de tempo. A primeira desova com quatro anos e a segunda, após o segundo ano de vida. A fecundidade de uma tainha de $41 \mathrm{~cm}$ chega a 300000 óvulos. Os parasitos mais comuns são crustáceos Co. pepoda, que vivem em suas brânquias.

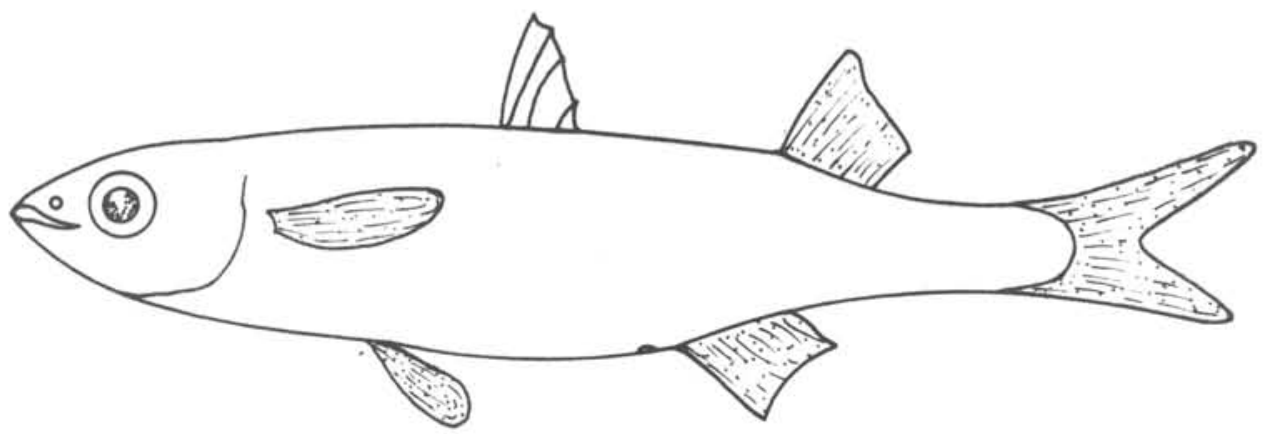

Fig. 2 - Curimã, Mugil lisa.

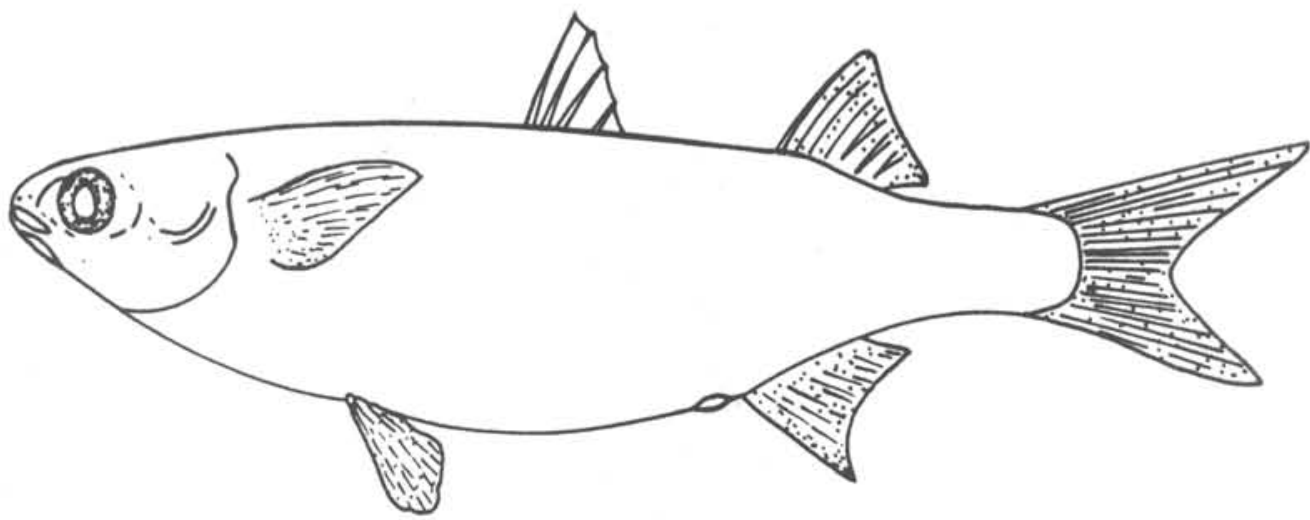

Fig. 3- Tainha, Mugil curema.

O peso da curimã varia de $5 \mathrm{~g}$ a $4 \mathrm{~kg}$ com comprimento total começando com $9 \mathrm{~cm}$ e terminando com $78 \mathrm{~cm}$; a tainha varia de 9 a $710 \mathrm{~g}$, em exemplares de $9 \mathrm{~cm}$ até $41 \mathrm{~cm}$. Uma tainha do mesmo tamanho que uma curimã é mais pesada do que esta. A cor dos olhos da tainha jovem é alaranjada, sendo levemente amarelada na curimã; a distinção dos adultos é mais fácil.

Moura, Silva \& Vasconcelos Filho (1972) tentaram determimar a idade da tainha pela leitura das escamas, mas verificaram que apenas alguns exemplares apresentavam anéis nessas estruturas, e que a leitura era difícil por causa da pequena diferenciação dos anéis. Entretanto, Schubart (1936) conseguiu fazer a leitura e verificou que a curimã atinge o primeiro ano de vida com 16 a $20 \mathrm{~cm}$, o segundo com $26 \mathrm{~cm}$, o terceiro com $32 \mathrm{~cm}$ e o quarto com $49 \mathrm{~cm}$, ao passo que a tainha, $29 \mathrm{~cm}$ no segundo ano (não apareceu nenhum com um ano), 37 no terceiro e $41 \mathrm{~cm}$ no quarto. Acompanhando o deslocamento das curvas de frequêencia de comprimentos, os autores supra encontraram $15,5 \mathrm{~cm}$ e $41 \mathrm{~g}$ para o primeiro ano da tainha, 28 $\mathrm{cm}$ e $233 \mathrm{~g}$ para o segundo ano e $37,5 \mathrm{~cm}$ e $549 \mathrm{~g}$ para o terceiro ano. os dois primeiros dados aproximando-se dos encontrados por Schubart (1936) quanto aos comprimentos.

Silva \& Moura (1972) fizeram experiências de criação da tainha e da curimã, quatro em redes fixas e duas em redes flutuantes, de março de 1970 a abril de 1971 . Foram determinadas as taxas de crescimento, as quais, conforme o tamanho dos peixes, variaram mensalmente de 0,36 a $2,13 \mathrm{~cm}$.

Silva (1975) cultivou experimentalmente a tainha e estudou a variação da sua biomassa.

Mugil lisa ocorre do Rio Grande do Norte ao Rio Grande do Sul. Ela cria-se em água salobra da embocadura dos rios e posteriormente vai para o mar. E comum nas Lagoas de Patos e Mirim, de abril a junho, saindo para o oceano em enormes cardumes (Barcellos, 1966). Atinge $1 \mathrm{~m}$ de comprimento total e $6 \mathrm{~kg}$ de peso. No porto de Rio Grande foram desembarcadas $344 \mathrm{t}$ em 1959 , $1302 \mathrm{t}$ em 1960, 1077 t em 1961 e $935 \mathrm{t}$ em 1962 (Barcellos, 1966).

Famosas são as capturas de tainhas no litoral paulista, notadamente em Ubatuba. Schmidt (1948) menciona que num só lance, perto da Illha Anchieta, SP, foram capturados 45000 exemplares em 1917! Entretanto, a captura total de 1943 foi estimada em apenas 16000 exemplares, não havendo dados mais recentes sobre quantidades de tainhas no litoral paulista.

$\mathrm{Na}$ Itália a desova artificial da espécie Mugil cephalus fo conseguida em 1930. A indução da sua desova foi feita em 1964 por Yun-An Tang, do Taiwan Fisheries Research Institute, que injetou o hormônio sintético "Sinahorin" e extrato hipofisário de Mugil cephahus. A desova ocorreu 20 a 24 horas após a injeção, e cerca de $70 \%$ das fêmeas tratadas desovaram. O método fo aperfeiçoado em Israel a partir de 1968 (Bardach, Ryther \& Mc Larney, 1972). Embora o método da hipofisação tenha sido descoberta no Brasil por Ihering, Cardoso \& Pereira (descrito por Ihering em 1937), não está sendo aplicado nas espécies existentes nos viveiros pernambucanos. No Nordeste é costume capturar exemplares pequenos ("sementes"), de 10 a $15 \mathrm{~cm}$ de comprimento, em agosto e setembro, que são colocados nos viveiros para engorda (Nomura, 1978).

\section{Biologia dos Centropomidae}

Sabe-se que a época de reprodução do robalo vai de maio a setembro, quando procura os lagos que se comunicam com os rios, a fim de proceder à desova em águas calmas.

Na década de 1930 foi tentada a sua aclimatação na represa de Santo Amaro, SP, sem resultados positivos.

Magalhães (1931) manteve 17 robalos, Centropomus undeci. malis, em aquário com capacidade para 4000 litros de água, no período de 15 de setembro de 1930 a 15 de junho de 1931 , em São Paulo. No mesmo tanque ele colocou diversos lambaris, Astyanax spp., que à noite eram apanhados pelos robalos. Na opinião de Magalhães a espécie aclimata-se bem em cativeiro, e seria o peixe indicado para povoar lagos e rios do interior, em locais onde a temperatura não fosse muito baixa.

A criação do robalo em cativeiro foi recomendada por Carvalho em 1943. No mar ela se alimenta de pequenos peixes, como sardinhas e manjubas, e alguns crustáceos (camarões). Nas regiōes pantanosas alimenta-se também de insetos e larvas aquáticas.

Silva \& Vasconcelos Filho analisaram o conteúdo estomacal de Centropomus undecimalis e Centropomus parallelus. Ambas nutrem-se de peixes e crustáceos e, esporádicamente, de vegetais. 
A primeira mostra preferèneia por peixes (44\%), onquanto que a sogunda nor crustáceos $(55 \%)(1972)$.

Uma temea de $80 \mathrm{~cm}$ de comprimento total possul ovários de $20 \mathrm{~cm}$ de comprimento por $4 \mathrm{~cm}$ de largura, pesando $200 \mathrm{~g} \mathrm{e}$ encerrando milhōes de óvulos.

Em 1975 houve captura de $43,5 \mathrm{t}$ om Santa Catarina e 2,6 t em São Paulo. No Rio de Janeiro a produção de 1974 foil de 10,4 t. Segundo Silva (1967-69), Centropomus undecimalis apresenta $16,2 \%$ de proteínas e 1,2 a $2,9 \%$ de gorduras, ao passo que $M u$. gill curema, $18,98 \%$ de proteínas e 1,64 a $3,2 \%$ de gorduras.

\section{Pesquisas}

O Departamento de Oceanografia da Universidade Federa de Pernambuco possui uma estação de piscicultura na Itha de Itamaracá desde 1966, onde desenvolve pesquisas sobre o cultivo de peixes estuarinos em escala comercial, em 28 viveiros, cobrindo uma área de 28 hectares. A finalidade é a de determinar o melhor tipo de criação para espécies de valor comercial, registro das taxas de sobrevivência e crescimento dessas espécies, determinação da relação peixe-área e da taxa de conversão alimentar com diversos tipos de alimentos (Silva, 1976).

O método da policultura foi adotado nesses viveiros, para determinar o tipo de cultura mais adequado para as espécies de importáncia comercial (Cavalcanti, 1977). Verificou-se que a melhor taxa de crescimento ocorre com a curimã, que atinge $1 \mathrm{~kg}$ em apenas um ano, sendo mais lento o crescimento da tainha. Taxas de sobrevivência de 70 a $80 \%$ foram obtidas com a combinação Mugill curema

Centropomus undecimalis, e 95\% com Mugil lisa - Centropo. mus undecimalis. Sem alimentação artificial, ou fertilização, a produção da combinação Mugil curema, Centropomus undecimalis e Gerridae (Eugerres olisthostoma, Eugerres rhombeus e Eugerres bra. silianus) variou de 400 a $800 \mathrm{~kg} / \mathrm{ha} / \mathrm{ano}$, enquanto que para $\mathrm{Mu}$. gil lisa e Centropomus undecimalis chegou a $1050 \mathrm{~kg} / \mathrm{ha} / \mathrm{ano}$ e para Mugil curema, Mugil lisa e Gerridae, $1100 \mathrm{~kg} / \mathrm{ha} / \mathrm{ano}$. Com fertilizacão. a taxa de produção de Mugil cırema, Centropomus undecimalis e Gerridae, variou de 700 a $900 \mathrm{~kg} / \mathrm{ha} / \mathrm{ano}$, enquanto que a mesma combinação com alimentação artificial variou de 800 a 1300 $\mathrm{kg} / \mathrm{ha} / \mathrm{ano}$ e para Mugil lisa e Centropomus undecimalis, $1500 \mathrm{~kg}$ / ha/ano.

\section{Recomendaçōes}

Há carência de proteína animal, de baixo custo. Uma das maneiras fáceis de se obter esse produto é com a criação de peixes em viveiros. Para que os viveiros existentes no Nordeste produzam mais peixes por ha/ano recomendamos:

1 - controle diário da entrada e saída de água, dotando todos os viveiros de comunicação com o Canal de Santa Cruz;

2 - aumentar a profundidade dessas construções, para receber maior volume de água;

3 - eliminar as espécies carnívoras;

4 - fornecer alimentação adequada diariamente, para obtenção de melhor taxa de conversão alimentar;

5 - adotar o método da hipofisação, em vez de simplesmente capturar "sementes" (exemplares pequenos)' para engorda; dessa maneira maior será a quantidade de alevinos a ser criada nos viveiros:

6 - construir mais viveiros no Nordeste, assim como introduzi- los no Sul, que possui locais adequados para tais tipos de am. bientes,

7 - criąĩo de robalos em úgua doce, haja visto a sua fácil aclimatan ç̃o; nesse caso seria necessúria a criaçđo paralela de peixes forrageiros, como lambaris, Astyanax spp, is saguinus, Curi. marus spp.

\section{Bibliografia}

BARCELLOS, B.N, 1966. Informe geral sobre a pesca no Rio Grande do Sul. Porto Alegre, Banco Regional do Desenvolvimento do Extremo Sul, 120p.

BARDACH, J.E.; RYTHER, J.H. \& MCLARNEY, W.O. 1972 Aquaculture: the farming and husbandry of freshwater and marine organisms. New York, Wiley-Interscience, xii + 868p.

CARVALHO, J. de P. 1943. O robalo. Notas agríc., $6: 143-148$.

CAVALCANTI, L.B. 1977. Polyculture trials in Brazil. F.A.O. Aquic. Bull., $8(3 / 4): 3-4$ -

IHERING, $R$, von 1937. A method for inducing fish to spawn. Progve Fish Cult., (34) : 15-16

MACEDO, S.J.; LIRA, M.E. F. \& SILVA. J.E. 1973. Condiçōes hidrológicas do Canal de Santa Cruz - Itamaratá, PE. Bolm Recursos nat., SUDENE, 11 (1/2) :55-92.

MAGALHĀES. A.C. de 1931. Monografia brazileira de peixes fluviaes. São Paulo, Lanzara \& Zanin, 262p.

MOURA, S.J.C.; SILVA, J.E. \& VASCONCELOS FILHO, A.L. 1972. Dados preliminares sobre crescimento, recrutamento e relação peso/comprimento da tainha, Mugil curema Valenciennes, em estuário do Nordeste Oriental do Brasil. Anais Inst. Ciênc. biol. Univ. fed. rur. Pernambuco, 2 (2) : 43-52.

NOMURA, H. 1978. Ictiologia e piscicultura, 3? ed. São Paulo, Nobel, $118 \mathrm{p}$.

SCHMIDT, C.B. 1948. Alguns aspectos da pesca no litoral paulista. Revta Mus. paul., n.s., $1: 1-34$.

SCHUBART, O. 1936. Investigaçōes sobre os vivetros do Recife. Bolm Secr. Agric. Ind. Com. Est. Pernambucn, 1 : 153-176.

SILVA, J.E. 1967-69. Nota prévia sôbre viveiros de peixes situados em Itamaracá, Pernambuco (Brasil). Trabhs oceanogr. Univ. fed. Pernambuco, 9/11:317-324.

- Cultivo da tainha (Mugil curema Valenciennes, 1836) em condiçōes experiementais: estudo da variação da biomassa. Tese. Universidade de São Paulo, Instituto de Biociências, $74 \mathrm{p}$.

tura estuarina na costa nordestina do Brasil. In: Anais do I Encontro Nacional sobre Limnologia, Piscicultura e Pesca Continental, Belo Horizonte, p. 241-24.5.

----- ; LIRA, M.E.F. \& MACEDO, S.J. 1969. Consideraçōes hidrológicas sobre viveiros de peixes de Itamaracá (PE). Bolm Estud. Pesca, 9 (2) : 27-42.

- - - - \& MOURA, SJ.C. 1972. Experimento de cultivo de tainhas Mugll spp. em redes - análise crítica sobre dados de crescimento. Anais Inst. Ciênc. biol. Univ. fed. rur. Pernambuco, 2 (2) : 123-144.

- - - \& VASCONCELOS FILHO, A.L. 1972. Aspectos gerais sobre a alimentação de camorins (Centropomus undecima. lis Bloch e Centropomus parallelus Poey). Anais Inst. Ciênc. biol. Univ. fed. rur. Pernambuco, 2 (2) :23-41. 